\title{
FENOLOGIA, BIOLOGIA FLORAL E DISPERSÃO DE Simarouba amara AUBL. (SIMAROUBACEAE) EM MATA CILIAR NA CHAPADA DIAMANTINA, BAHIA
}

\author{
Idelmara Pereira de Souza ${ }^{1}$; Ligia Silveira Funch ${ }^{2}$ \\ 1. Bolsista PROBIC/UEFS, Graduando em Bacharelado em Ciências Biológicas, Universidade Estadual de Feira de \\ Santana, e-mail: delsouza2010@hotmail.br \\ 2. Orientador, Departamento de Ciências Biológicas, Universidade Estadual de Feira de Santana, e-mail: \\ ligiafunch@yahoo.com
}

PALAVRAS-CHAVE: Biologia floral; dispersão; sazonalidade.

\section{INTRODUÇÃO}

Simaroubaceae possui distribuição tropical, com 20-30 gêneros (Thomas 1990) e aproximadamente 200 espécies (Cronquist 1981). A família é caracterizada por produzir grande quantidade de substâncias amargas, em sua maioria, com propriedades farmacológicas (Muhammad et al. 2004). O gênero Simarouba apresenta apenas duas espécies no Brasil. Uma delas, Simarouba amara Aubl. é constantemente encontrada e utilizada em áreas de reflorestamento (Lima 2009, Soares 2009, Alencar 2011). E, embora se trate de um importante componente das formações florestais brasileiras, não são encontrados estudos voltados para compreender a sua biologia floral e os mecanismos de polinização e dispersão, essenciais para o entendimento das estratégias reprodutivas da espécie e manutenção das populações.

Uma ferramenta que há muito vem sendo utilizada para a compreensão das estratégias reprodutivas de espécies vegetais é a fenologia, a qual estuda a ocorrência de eventos biológicos periódicos e sua relação com fatores bióticos e abióticos (WilliamsLinera \& Meave 2002).

Relacionado ao entendimento do comportamento fenológico das plantas, estão estudos focados na biologia floral e processo de dispersão de sementes de espécies vegetais. Sendo o primeiro, voltado para o estudo das manifestações de vida da flor, dando suporte para o entendimento das interações entre as flores e seus polinizadores (Faegri \& van der Pijl 1979). Enquanto que o segundo consiste na compreensão dos tipos e componentes estruturais dos frutos, a fim de caracterizar seus possíveis agentes dispersores.

As relações entre as flores e seus polinizadores, bem como frutos e seus dispersores, são frequentemente interpretadas como resultados de interações em que as estruturas em questão são adaptadas ao transporte/propagação mediado pela ação de vetores (biótico/abióticos). Portanto, a polinização e dispersão, são processos chave na vida das plantas que influenciam seus ritmos de floração e frutificação (Williams-Linera \& Meave 2002).

Dessa forma, este projeto propôs complementar as informações disponíveis na literatura para $S$. amara, identificando os padrões foliares e reprodutivos da espécie, em associação a sua biologia floral e mecanismos de polinização e dispersão em ambiente ciliar, frente às condições climático-ambientais as quais a espécie está submetida.

\section{MATERIAL E MÉTODOS OU METODOLOGIA (ou equivalente)}

As observações fenológicas foram realizadas mensalmente em 29 indivíduos de Simarouba amara marcados em trilhas na mata ciliar do rio Lençóis (12 33'34”S e $41^{\circ} 24$ '15"), município de Lençóis, Bahia, iniciando-se em junho de 2013 e findando em maio de 2016. Foram acompanhadas fenofases foliares (queda foliar e brotamento) e reprodutivas (botão, flor, fruto imaturo e fruto maduro), determinando sua intensidade 
em escala semi-quantitativa (Fournier, 1974), além da sincronia dos indivíduos na população e separadamente em indivíduos femininos e masculinos (Bencke \& Morellato, 2002).

Correlações de Spearman (rs) foram realizadas para investigar a influência das variáveis ambientais (temperatura, precipitação, umidade e fotoperíodo) sobre as fenofases. Análises circulares foram realizadas para testar a sazonalidade das fenofases com base na frequência dos eventos. Foram consideradas sazonais as fenofases que apresentaram comprimento do vetor $r$ acima de 0,5 (Morellato et al. 2010), e teste de Rayleigh significativo.

As observações de biologia floral foram realizadas em três indivíduos (dois femininos e um masculino) em outubro/2015. Foram coletadas 32 flores estaminadas, para verificação de viabilidade polínica, presença de osmóforos e pigmentos que refletem raios ultravioleta, e oito pistiladas para avaliação da receptividade estigmática, além de observações da antese e duração das flores (Dafni et al. 2005). Para o estudo de dispersão foi utilizado o método do indivíduo focal (Altmann 1974), registrando a presença e número de frugívoros/espécie, horário e comportamento de forrageio dos animais, realizado no mês de dezembro de 2015 em dois indivíduos, totalizando 09 horas de duração.

\section{RESULTADOS E/OU DISCUSSÃO (ou Análise e discussão dos resultados)}

Simarouba amara apresentou padrão foliar perenifólio e alta sincronia para as fenofases vegetativas. A produção e queda foliar foram contínuas ao longo dos meses, sempre em baixa intensidade $(<40 \%)$, e brotamento com maior atividade no fim do período seco e início do período chuvoso (Figura 1), quando há aumento do fotoperíodo, a única variável significativamente correlacionada a esta fenofase.

A floração da população de $S$. amara se mostrou anual intermediário com três meses de duração (Figura 1) e em alta sincronia (Figura 2). De forma sazonal $(p<0,05)$, botão e flor ocorreram no fim da estação seca, entre os meses de agosto e novembro, com data média em setembro e outubro, respectivamente. Botão e flor exibiram correlação negativa $(\mathrm{p}<0,05)$ apenas com a umidade.

Os indivíduos femininos exibiram comportamento anual intermediário, com botão e flor incidindo nos meses de setembro e outubro (Figura 1). Enquanto os indivíduos masculinos exibiram seus botões e flores entre agosto e novembro e em maior intensidade. Segundo Bawa (1983), em espécies dióicas a fase estaminada precede a pistilada, podendo também ser mais longa, e ainda afirma que as plantas masculinas geralmente apresentam maior número de flores que as femininas, como observado neste estudo.

A espécie exibiu frutificação anual intermediária em baixa sincronia (Figura 1), ocorrendo predominantemente no período chuvoso. Os frutos imaturos sucederam na estação chuvosa, entre os meses de outubro e dezembro e se mostraram sazonais $(\mathrm{p}<0,05)$ com data média entre outubro e novembro. Já os frutos maduros, além de ocorrerem no período das chuvas, podem alcançar o início da estação seca, revelando-se sazonal $(\mathrm{p}<0,05)$ com data média entre dezembro e janeiro. Somente o fruto imaturo apresentou correlação negativa com a umidade e positiva com o fotoperíodo $(\mathrm{p}<0,05)$.

A espécie apresentou antese noturna iniciando-se por volta das $23 \mathrm{~h}$ e finalizando em torno das 3-4h da manhã, durando de 4 a 5 h. Após o término da antese todos os estigmas avaliados estavam receptivos. Entretanto, nenhum dos grãos de pólen coletados logo após a antese, ou aqueles coletados 15 horas depois, não estavam viáveis. Possivelmente a espécie necessite de um maior período para a maturação de seu pólen. As flores apresentaram osmóforos espalhados nas pétalas, além de pigmentos que 
refletem raios ultravioleta intensificando a coloração das pétalas. A presença destes mecanismos estão relacionados à atração de insetos (Faegri \& van der Pijl 1974) e associados auxiliam e/ou guiam os polinizadores às flores, principalmente em espécies como $S$. amara que possui flores pouco vistosas.

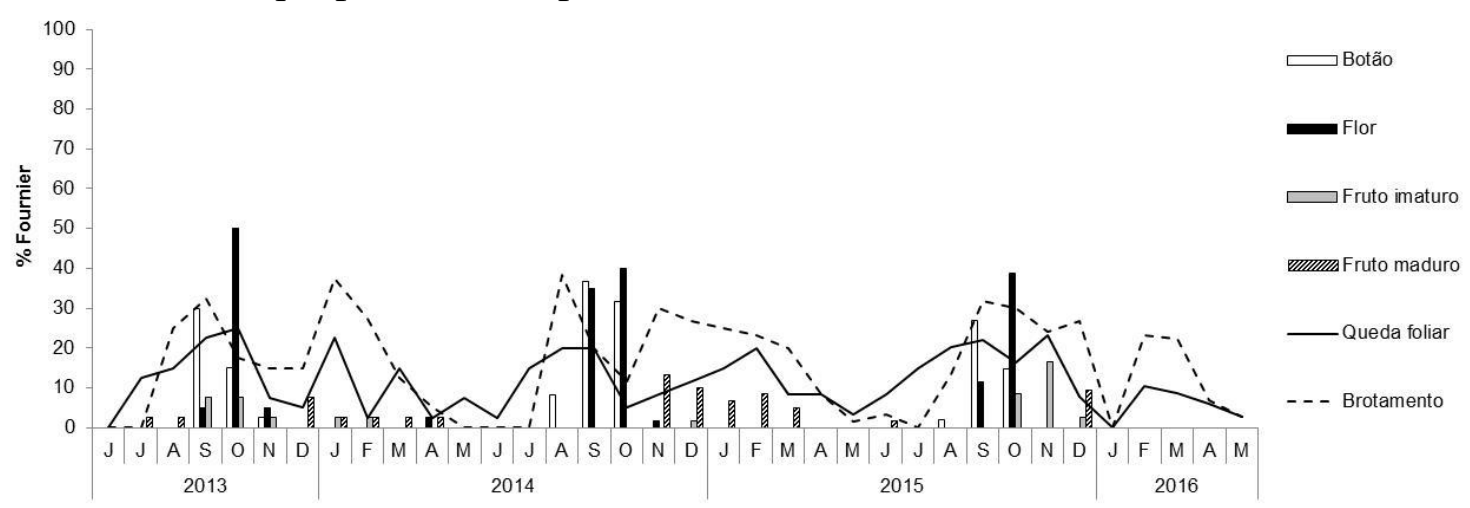

Figura 1: Intensidade das fenofases de Simarouba amara Aubl. na mata ciliar do rio Lençóis, Chapada Diamantina, Bahia.

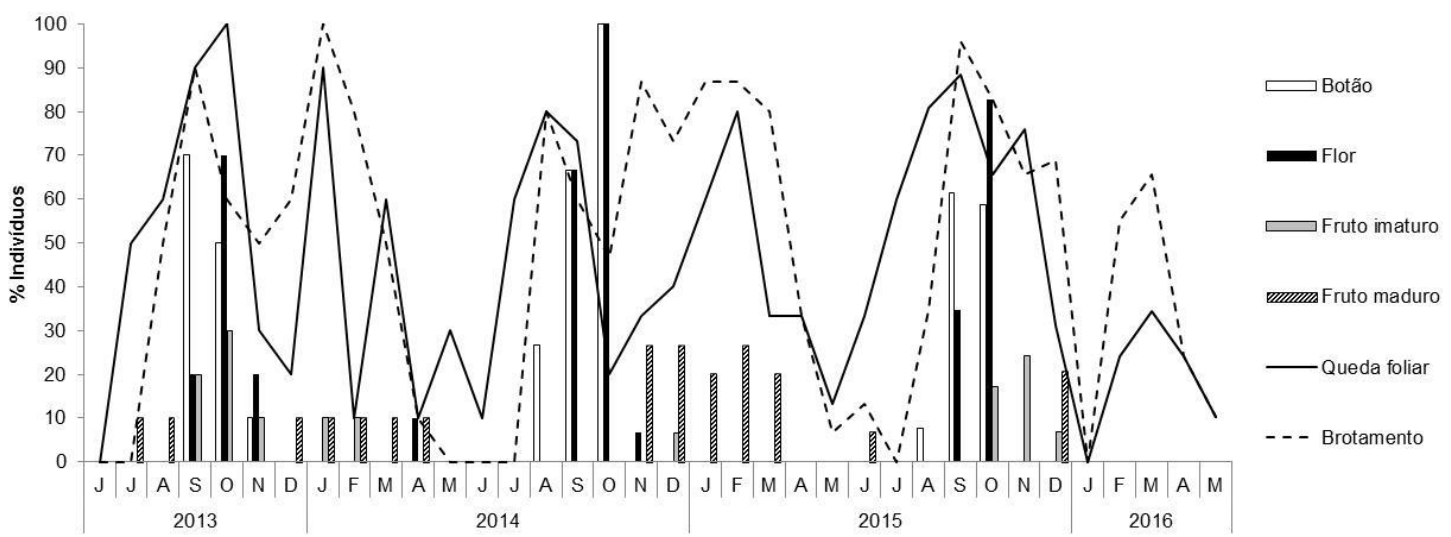

Figura 2: Sincronia intraespecífica das fenofases de Simarouba amara Aubl. na mata ciliar do rio Lençóis, Chapada Diamantina, Bahia.

Durante as observação de dispersão a planta recebeu apenas uma visita, com duração de pouco mais de dois minutos, seguida do consumo de um fruto maduro. $\mathrm{O}$ frugívoro encontrado trata-se de uma ave, provavelmente uma fêmea da espécie Dacnis cayana, a qual já foi identifica consumindo frutos de outra espécie ocorrente na floresta ciliar do rio Lençóis. A baixa disponibilidade de frutos no período de observações da dispersão pode ter reduzido seu consumo, ou ainda porque durante a época chuvosa muitas espécies estão frutificando na região (Funch et al. 2002) aumentando a competição por frugívoros.

\section{CONSIDERAÇÕES FINAIS (ou Conclusão)}

A avaliação fenológica de Simarouba amara ao longo de 36 meses permitiu identificar com maior acurácia os padrões fenológicos e confirmar seu comportamento perenifólio e sazonal para os eventos reprodutivos. A espécie se mostrou mais sensível às variáveis ambientais, em especial umidade e fotoperíodo. A alta sincronia da floração associada aos osmóforos e pigmentos que refletem raios U.V. encontrados configuram estratégias para atração de polinizadores.

\section{REFERÊNCIAS}


ALTMANN, J. 1974. Observational study of behavior: sampling methods. Behavior 49: $227-265$

BAWA, K. S. 1983. Patterns of flowering in tropical plants. In: JONES, C. E.; LITTLE, R. J. (eds.) Handbook of experimental pollination biology. Van Nostrand Reinhold. New York, p. 394-410.

FAEGRI, K., Van Der PIJL, L. 1979. The Principles of Pollination Ecology. 3 ed. Oxford: Pergamon Press, p. 115-119.

FUNCH, L. S.; FUNCH, R.; BARROSO, G. M. 2002. Phenology of gallery and montane forest in the Chapada Diamantina, Bahia, Brazil. Biotropica, v.34, p. $40-50$. WILliAMS-LINERA, G.; MEAVE, J. 2002. Patrones fenológicos. In: GUARIGUATA, M. R.; KATTAN, G. H. (eds.). Ecología y conservación de bosques neotropicales. Costa Rica, Libro Universitario regional.

CRONQUIST, A. 1981. An integrated System of Classification of the Flowering Plants. New York, Columbia University.

DAFNI, A.; KEVAN, P. G. \& HUSBAND, B. C. 2005 (Ed.). Practical pollination biology. Cambridge: Enviroquest. 590 p

LIMA, T. A. 2009. O papel de plantios homogêneos de espécies florestais nativas em promover a regeneração natural na Amazônia Central. Dissertação de Mestrado. Instituto Nacional de Pesquisa da Amazônia-INPA.

MORELlATO, L. P. C.; ALBERTI, L. F. HUDSON, I. L. 2010. Applications of circular statistics in plant phenology: a case studies approach. In. KEATLEY, M.; HUDSON, I. L. (Org.). Phenological Research: Methods for Environmental and Climate Change Analysis. Springer, v. 1, p. 357-371.

MUHAMMAD, I.; BEDIR, E.; KHAN, S. I.; TEKWANI, B. L.; KHAN, I. A.; TAKAMATSU, S.; PELLETIER, J.; WALKER, L. A.; 2004. A new-antimalarial quassinoid from Simaba orinocensis. J Nat Prod. 62: 772-777.

THOMAS, W. W. 1990. The American genera of Simarubaceae and their distribution. Acta Bot. Bras., v. 4, n. 1, p. 11-18. 